\title{
Especial
}

\section{EL INTENTO DE DEFINIR LA ESTÉTICA DE LADANZA NEGRA}

\section{TENTANDO DEFINIR A ESTÉTICA NEGRA EM DANÇA}

TRYING TO SET THE BLACK BEAUTY IN DANCE

Nadir Nóbrega Oliveira

Nadir Nóbrega Oliveira PhD en Artes Escénicas: Danza por el Programa de Posgrado en Artes Escénicas de la Universidad

Federal de Bahía. Profesora Adjunta del Curso de Licenciatura en Danza de la Universidad

Federal de Alagoas, Directora del Museo Théo Brandão de Antropología y Folclore de la Universidad Federal de Alagoas. 


\section{Resumen}

En este artículo trato de contextualizar los comentarios sobre las coreografías desarrolladas por mí y por otros coreógrafos en los blocos afro de carnaval: Bankoma, llê Aiyê, Malê Debalê y Olodum; coreografías de muchos significados y movimientos, aplicando mis conocimientos asimilados durante el doctorado en el Programa de Posgrado en Artes Escénicas, de la Universidad Federal de Bahía, así como los contenidos aprendidos en Danza Moderna y Danzas Africanas como bailarina y estudiante del profesor Clyde Wesley Morgan y del coreógrafo Buly Soukol, del Ballet la Linguér, Senegal. Palabras clave: Blocos afro, Coreografía, Estética negra.

\section{Resumo}

Neste artigo, procuro contextualizar observações sobre as coreografias desenvolvidas por mim e por outros coreógrafos nos blocos afro carnavalescos Bankoma, llê Aiyê, Malê Debalê e Olodum, cheias de significados e de movimentos, aplicando meus próprios conhecimentos, assimilados durante o doutorado no Programa de PósGraduação em Artes Cênicas, da Universidade Federal da Bahia, bem como conteúdos aprendidos em Dança Moderna e Danças Africanas, enquanto dançarina e aluna do professor Clyde Wesley Morgan e do coreógrafo Buly Soukol, do Balé La Linguér, Senegal.

Palavras-chave: Blocos afro, Coreografia, Estética negra.

\section{Abstract}

In this article, I try to contextualize observations about the choreographies developed by other choreographers and myself in the Afro-Carnival groups Bankoma, Ilê Aiyê, Malê Debalê, and Olodum, full of meanings and movements, applying my own knowledge assimilated during the $\mathrm{PhD}$ Program in Performing Arts from Universidade Federal da Bahia, as well as content learned in Modern Dance and African Dances as a dancer and student of Professor Clyde Wesley Morgan and choreographer Buly Soukol, from Balé La Linguér, Senegal.

Keywords: Afro groups, Choreography, Black esthetics. 
Desde la adolescencia, las artes forman parte de mi vida. Me arriesgaba a cantar en rezos a Santo Antonio, en las clases de canto del coral de la escuela João Florêncio Gomes, y también me gustaba bailar merengue y twist, en las pequeñas fiestas del barrio en que vivía.

Fue en la secundaria, como alumna del curso técnico de Administración, en el Colegio Estatal M. A. Teixeira de Freitas, en el barrio de Nazaré, Salvador, donde formalicé mi interés por las Artes, en las clases de teatro y de filosofía, con los profesores Reinaldo y Ricardo Líper. Comencé mi carrera de bailarina profesional, en este período, participando del grupo parafolclórico Olodumaré, durante cuatro años, bailando en varios escenarios de países europeos.

Al bailar en grupos aficionados y profesionales, aprendí muchas cosas acerca de las culturas negro-brasileña y negro-africana, con destaque para el Grupo de Danza Contemporánea de la Universidad Federal de Bahía, bajo la dirección del coreógrafo afroamericano Clyde Wesley Morgan. Entre los recuerdos danzantes de mi juventud, el carnaval ocupa un lugar privilegiado en mi historia de vida. Así, la búsqueda por la creación artística y por la transmisión de saberes que implican cuerpo, danza, memoria, ancestralidad y oralidad, me hicieron desarrollar un proyecto de investigación, en el doctorado, derivado de aspectos étnicos de los blocos afro: llê Aiyê, Olodum, Malê Debalê y Bankoma, que constituyen una de las más importantes expresiones de la cultura afrobrasileña presente en Bahía.

Hasta hoy, sigo del lado de dentro de esos objetos de investigación y, entre las fuentes utilizadas, hubo un campo principal, en que conduje mi etnografía acerca de las coreografías desarrolladas y allí contextualizadas, por medio de la perspectiva de la etnoescenología, con mis alumnas del bloco afro Bankoma, en el período del 2006 al 2008, coreografías que fueron enriquecidas por la música percusiva, por los accesorios para manos y cabeza, y por los vestuarios de ese bloco.

Partiendo de la óptica de Pradier (1997, p. 9), la etnoescenología aporta a las artes escénicas un enfoque pluricultural y proporciona entendimientos sobre el cuerpo que se expresa, espectacularmente, por sus varias experiencias y memorias colectivas.

Así, bajo la óptica de la etnoescenología, apunto que la espectacularidad de las danzas negras de los blocos afro estudiados no es un sistema 
codificado de danzas occidentales, como observamos en las técnicas de danza norteamericanas y europeas (ballet, danza moderna, danza expresionista alemana, jazz, entre otras). En los procesos de creación y en mis clases se tuvieron en cuenta algunos principios básicos de la cultura negra, por ejemplo, actuar siempre en comunión con los elementos de lo sagrado, sin estereotipar o fingir que se está en trance, pues, para aquellos(as) jóvenes, el candomblé es el eslabón con la ancestralidad.

Esas asociaciones culturales carnavalescas, popularmente conocidas como blocos afro, constituyen una de las más importantes expresiones de la cultura afrobrasileña presente en Bahía. Desde la fundación, bajo el comando de los tambores, los habitantes de los barrios, los juerguistas y turistas, cantan y bailan sus reivindicaciones, sus alegrías, sus homenajes a los antepasados, a sus héroes, sobre todo, al continente africano - terra mater - la casa de origen de la diáspora negra, reactualizando y recreando la memoria ancestral.

Desde la perspectiva "desde dentro" y como estudiosa de esas prácticas, en la ciudad de Salvador, Bahía, puedo hablar con el valor de pertenencia acerca de los procesos de acciones sociopolíticas y culturales (creaciones artísticas, formaciones profesionales, construcciones de identidades), que esos blocos desarrollan en sus barrios de origen: el llê Aiyê, en el Curuzu; el Olodum, en el Pelourinho; el Malê Debalê, en Itapuã; y el Bankoma, en Portão. Las acciones de esos blocos afro anteceden la Ley 10.639, de 9 de enero del 2003, modificada para la Ley $11.645,1$ de 10 de marzo del 2008, que entra en vigor con la siguiente redacción:

Art. 26-A - En los centros de enseñanza primaria y de enseñanza secundaria, públicos y privados, se hace obligatorio el estudio de la historia y cultura afrobrasileña e indígena.

$\S 1$ 으 El contenido programático a que se refiere este artículo incluirá diversos aspectos de la historia y de la cultura que caracterizan la formación de la población brasileña, a partir de esos dos grupos étnicos, tales como el estudio de la historia de África y de los africanos, la lucha de los negros y de los pueblos indígenas en Brasil, la cultura negra e indígena brasileña y el negro y el indio en la formación de la sociedad nacional,

1. Esa Ley es un posible elemento de combate al prejuicio y a la discriminación étnico-racial a partir de la escuela en las cuestiones negras e indígenas. 
rescatando sus contribuciones en las áreas social, económica y política, pertinentes a la historia de Brasil.

$\S 2^{\circ}$ Los contenidos referentes a la historia y cultura afrobrasileña y de los pueblos indígenas brasileños serán impartidos en el ámbito de todo el currículo escolar, en especial en las áreas de educación artística y de literatura e historia brasileñas. (BRASIL, 2008, s/p, tradução nossa)

Es pertinente resaltar la importancia de los procesos históricos que culminaron en la aprobación de la referida Ley, como el Motim do Maneta (1711), la Revolta do Terço Velho (1728), la Revolta de Búzios o Conjuração Baiana (1798) y la Revolta dos Malês (1835). Según Cunha Jr. (2001, p. 15), esos procesos históricos no deben omitirse, puesto que tal estudio "facilita una visión más igualitaria de la Historia de la humanidad".

Según los enseñanzas de Kabengele Munanga (1999), ninguna ley, en cualquier cultura, es capaz de destruir totalmente actitudes prejuiciosas. Sin embargo, creo que la Ley 11.645/2008 (BRASIL, 2008) contribuyó a la construcción de la identidad étnico-racial, en la formación de los educadores y en la educación, estimulando los cuestionamientos y la deconstrucción "de los mitos de la superioridad e inferioridad entre grupos humanos que fueron introyectados en estos por la cultura racista en que se socializaron" (MUNANGA, 1999, p. 17).

Para Oliveira (2013, p. 29), "a identidad es una fuente de sentido de experiencia”. No existe una nación, un país o una persona sin nombre, lo que ya demuestra la diferencia. La identidad no es un descubrimiento, es también la construcción del conocimiento de uno mismo, en cuanto individuo. La identidad no existe sin la presencia del otro. Es una categoría de definición y de identificación, es decir, es la manera como nos vemos.

Cuando uso el término identidad, comprendo la dimensión del término y elijo su sentido en la cultura afrobrasileña: "a identidad cultural de cualquier pueblo corresponde idealmente a la presencia simultánea de tres componentes: el histórico, el lingüístico y el psicológico" (MUNANGA, 1999, p. 46).

En la ciudad de Salvador, tuvimos la minicomunidad Oba Biyí que, durante sus diez años de existencia (1976-1986), fue la primera experiencia de educación pluricultural en Brasil, bajo la iniciativa del Alapini Mestre 
Didi —Deoscóredes Maximiliano de los Santos_creada en el ámbito del llê Axé Opô Afonjá, ubicada en el barrio São Gonçalo do Retiro. Apoyando esa iniciativa, está la venerable lyá Oba Biyí "fundadora del Ilê Axé Opô Afonjá". Actualmente, en ese mismo espacio religioso, se fundó la Escuela Eugênia Anna dos Santos.

Otro espacio significativo de educación pluricultural es la Escuela Mãe Hilda, fundada en 1988 por lyalorisà Mãe Hilda Jitolú, y que se inició en su comunidad-terreiro, en la ladera del Curuzu, Bairro da Liberdade. Actualmente, esa escuela está ubicada en la sede del bloco afro llê Aiyê, en la misma calle. En ambas escuelas mencionadas, sus discentes, independientemente de cualquier credo religioso, estudian y aprenden con base en la tradición africano-brasileña e iorubana.

Esas escuelas y otras acciones socioeducativas de los blocos afro estudiados subsidian a los profesores y profesoras, y a los demás educadores y educadoras de la red de enseñanza formal e informal para poner en práctica las orientaciones emanadas de los Parámetros Curriculares Nacionales. Las sabidurías de los practicantes y de las practicantes también han sido incorporadas a la elaboración de este artículo, sin separar sus rutinas ritualísticas y educativas, condiciones heredadas, sobre todo, de las etnias africanas, que constituyen, así, las matrices estéticas negro-africanas/brasileñas, esenciales a la comprensión del mi análisis, prioritariamente, estético-artístico.

Los estudios acerca de la etnoescenología realizados por Armindo Bião et al. (2001), facilitaron mi comprensión sobre la espectacularidad. Así la explica Armindo: "Espectacularidad es la categoría de los juegos sociales donde el aspecto ritual propasa la rutina: son los rituales religiosos, las competiciones deportivas, los desfiles y mítines, las grandes fiestas" (2001 p. 163-164). Esa reflexión corrobora mi constatación de que esas prácticas negras tienen lugar en esos blocos afro, de manera natural y sencilla, entrelazándose, y, según Martins (2008, p. 38), están intrínsecamente conectadas a todo proceso religioso, que se entrelaza en una "unidad dinámica", equilibrada y armoniosa, del "cuerpo físico, emocional, espiritual e intelectual," contextualizado también por el antropólogo estadounidense Thompson como "filosofía holística"

Otros artistas brasileños también contribuyeron a nuestras construcciones identitarias latinoamericanas, cuyas obras artísticas y acciones contestaban las 
"viejas formas artísticas," orientadas por la estética europea que predominaba en la arte y en la literatura brasileña, en siglos pasados. Entre aquellos y aquellas figuran Mário de Andrade, Anita Malfatti y el maestro Heitor Villa-Lobos, cuyas acciones resonaron en varios espacios y cuyas prácticas produjeron frutos, con destaque para la Semana de Arte Moderna, realizada en el Teatro Municipal de São Paulo, entre los días 13 y 18 de febrero de 1922.

En el ethos educativo, Villa-Lobos luchó para que sus composiciones formasen parte de la vida y de la escuela brasileña y de los bailados, tales como: Caixinha de boas festas, Pedra bonita, Uirapuru, entre otras composiciones, como planteo en mi investigación acerca de la Danza afro, en Salvador/BA (OLIVEIRA, 1991, p. 23).

Resalto, también, las voluminosas obras completas de Mário de Andrade acerca del movimiento modernista, que implica la música brasileña, las artes plásticas de Brasil y los estudios de danzas brasileñas, publicados bajo el título de Danças dramáticas do Brasil (ANDRADE, 1982). Aunque la Semana de Arte Moderna no se haya convertido en el hecho más importante de la cultura brasileña, ya que, hasta entonces, solo las creaciones originadas del continente europeo eran consideradas arte, hizo que se instaurasen experimentaciones e investigaciones alrededor de la fundación de una arte nacional y de su propia estética. En ese proceso, no hay registro de que la danza haya sido presentada o contextualizada.

En la explicación de Pereira (2003, p. 91), "a primera escuela oficial de danza fue fundada en 1927, en Río de Janeiro", y otra en 1932, en la ciudad de São Paulo, por Chinita Ullman, que trajo la danza moderna europea, con enfoque en la danza expresionista alemana, aunque la danza siempre estuviera presente en varias partes de Brasil.

La trama provocada por la Semana de Arte Moderna se introdujo en las escuelas, originando una nueva forma de enseñar música y pintura, creando, así, un nuevo paradigma en la educación artística. Recuerdos esas influencias, sobre todo, en las clases de canto orfeónico, en que aprendí a cantar los himnos y otras canciones, con temas folclóricos brasileños. Entre las décadas de 1930 y de 1940, resalto dos entidades que tuvieron importancia fundamental en esa cuestión étnico-racial: la Frente Negra Brasileña, creada en la 


\section{Nadir Nóbrega Oliveira}

década de 1930 y el Teatro Experimental del Negro (TEN), fundado en la ciudad del Río de Janeiro, en 1944, que tuvo como idealizador el artista visual, actor, senador y profesor, Abdias do Nascimento.

Esas entidades estimularon el entendimiento de ser negro y negra y de ser respetados y respetadas, como seres humanos y todo nuestro legado, por el arte, por la educación y cultura brasileña. EI TEN tuvo varias actividades, en Río de Janeiro y en São Paulo, influenciando años después a la comunidad negra bahiana, con sus concursos de reina y piezas teatrales. En la opinión de Macedo (2006, p. 29), fue en el "período de 26 de agosto a 4 de septiembre de 1950, [que] el Distrito Federal albergó el I Congreso del Negro Brasileño" y tuvo, entre otros conferencistas, a la activista, coreógrafa y antropóloga afroamericana, Katherine Dunham.

En esa perspectiva, el TEN promovió una serie de eventos y contó con la colaboración de la bailarina y coreógrafa afrobrasileña, Mercedes Baptista, con el objetivo de desarrollar un intercambio entre las culturas norteamericana y brasileña (Figura 1). En una de sus clases de danza, "Miss Dunham solicitó a los presentes que improvisaran mostrando sus habilidades, de manera que Mercedes Baptista sobresalió y embarcó hacia Estados Unidos" (SILVA JR., 2007).

Figura 1 - La coreógrafa Mercedes Baptista, en presentación de danza, en la ciudad de Río de Janeiro

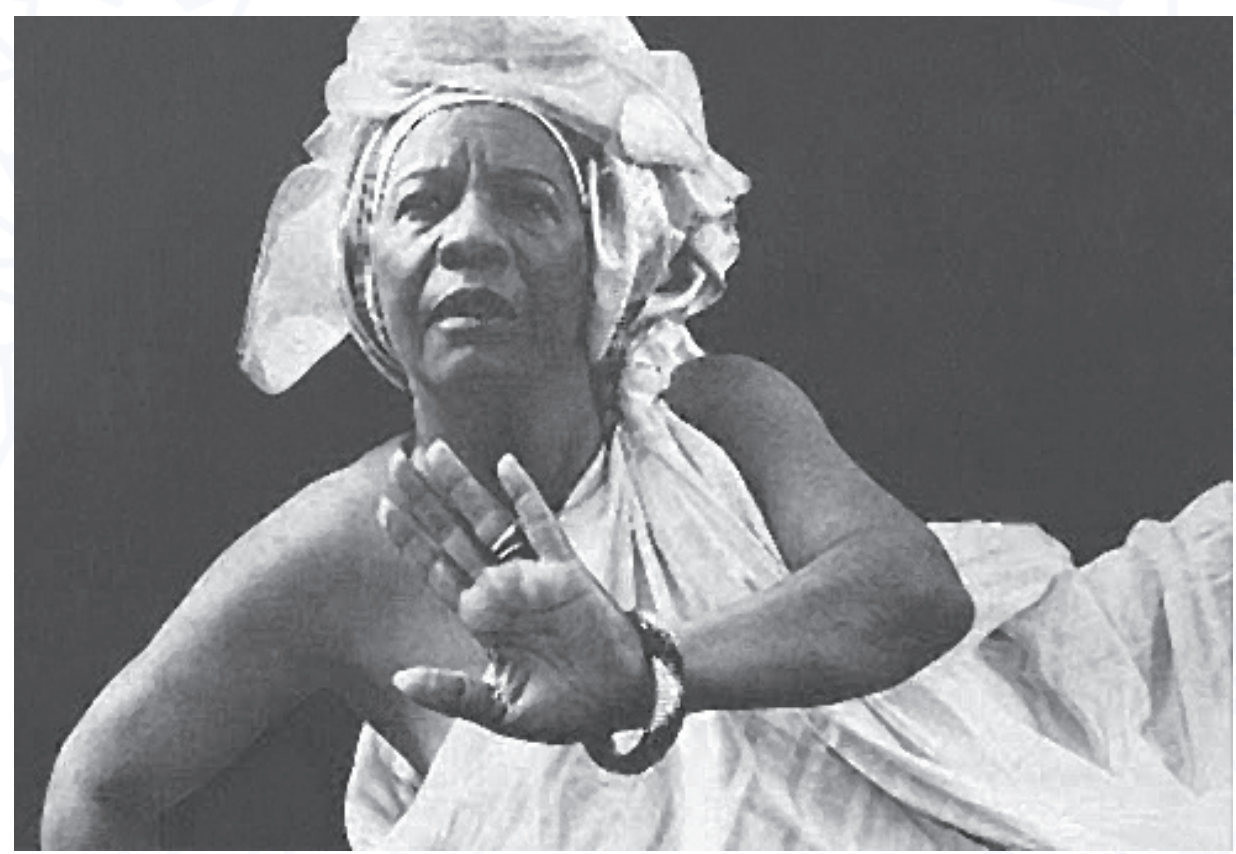

Fuente: Melo (2014) 
Mercedes Baptista, al regresar a Brasil, decide hacer lo mismo que hizo Miss Dunham en Estados Unidos, es decir, creó el Ballet Afrobrasileño, y, en la visión de Oliveira, quedó conocida como la "madre del ballet afro" y creó las coreografías Culto a Yemanjá, Lavagem do Bonfim y Cafezal, con la colaboración del babalorixá bahiano Joãozinho da Gomeia, y llevó a cabo varias presentaciones por Brasil.

Si, en los días actuales, aún es difícil para el(la) bailarín(a) negro(a) sobresalir y sobrevivir dignamente, y recibir remuneración por su trabajo profesional en danza, y sin los estereotipos establecidos por las imposiciones mercadológicas, jfigúrense en la década de 1940! Las clases de Mercedes Baptista, en la Escuela de Danza, situada en la Avenida Copacabana, en la ciudad de Río de Janeiro, fueron eficientes para un determinado grupo de alumnos y alumnas, tales como Marlene Silva, Isaura de Assis, Carlos Moraes y Domingos Campos, que sobresalieron en el mercado profesional internacional, y a quienes tuve la oportunidad de conocer, cuando aún era bailarina del grupo Olodumaré.

Otro movimiento significativo de la radicalización de la cultura brasileña fue el Tropicalismo, en la década de 1960, cuando Brasil estaba en pleno período de la Dictadura Militar, contestando todas las formas de autoritarismo y teniendo como principales líderes a los artistas bahianos Gilberto Gil y Caetano Veloso. Además de las cuestiones estéticas y literarias, el Tropicalismo revolucionó la cultura y la política brasileñas, como también movilizó a gran parte de la población con sus canciones inaugurales "Domingo no parque" (Gilberto Gil) y "Alegria, alegria" (Caetano Veloso). En el Tropicalismo, las cuestiones relacionadas con la diáspora africana estaban visibles en las letras de las canciones, en la apariencia estética de esos artistas, en los cortes de pelo, ropas, en las actitudes y en el comportamiento contestador. En aquella época, demostraban saber que querían participar en el lenguaje mundial, para fortalecernos como pueblo y afirmar nuestra originalidad.

Está vivo, en mis recuerdos, el impacto causado, al ver por la televisión de mi vecina de calle, Dona Edith, una comadrona, al cantor Gilberto Gil interpretando la canción "Domingo no parque", con el pelo al estilo black power. Según Caetano Veloso, citado por Almeida Jr. (2010, p. 19), el Tropicalismo "desestabilizó las jerarquías musicales, fundió lo erudito con lo popular, pasó por encima de las fronteras entre las clases sociales y entre niveles de educación". Así, puede 


\section{Nadir Nóbrega Oliveira}

considerarse un movimiento moderno brasileño, que proporcionó un teatro performativo, una nueva forma de escenificar con el cuerpo, cuestionando tradiciones cristianas, en fin, un movimiento que contribuyó a estimular las creaciones de una estética negra, un entendimiento de cuerpo. El redescubrimiento del trabajo contextualizado en el cuerpo, este que, según Jeudy (2002), puede ser visto como un "objeto de arte", y, de una manera intencional, la corporeidad "es una representación objetiva" (2002, p. 57), la danza, como referencia del cuerpo en movimiento, se presenta como un "enguaje de paso" (JEUDY, 2002, p. 68).

La ligereza de los cuerpos cuando se presentan, bailando en esos blocos afro, al ritmo de la percusión, contagia a punto de producir sensaciones y deseo de bailar. Además de eso, los movimientos de los cuerpos permiten fantasear el deseo de acercarnos a ellos y tocarlos. En esos cuerpos negros que bailan, cantan y tocan, quedan nítidas las variaciones de movimientos corporales, orientadas por las músicas percusivas. Cuerpos negros ondulados y danzantes, con los pies paralelos, deslizándose en la media punta y levantando los brazos. Me atrevo a afirmar que esos cuerpos negros, sujetos de la historia, alimentan la renovación artística de la danza y de la música brasileña.

\section{Comprensión de los "pilares fundamentales y estructurales"}

En esas creaciones artísticas estimulé a mis estudiantes, durante las clases y talleres que impartí en el bloco afro Bankoma, a captar sus realidades, por medio de la capacidad de observación, análisis e imaginación. A partir de sus referencias personales, condiciones socioculturales y de todas las impregnaciones que los rodeaban, volviéndose visualmente contemplables gracias a las combinaciones de los movimientos corporales. Se aportaron diversos estímulos para generar coreografías, con vistas a la proyección contemporánea de danza, intentando despertar también reflexiones acerca de qué es el continente africano y de cómo se enseñaba en las escuelas formales en que estudiaban. Para los montajes coreográficos, sin explicaciones previas, algunos procesos de pregunta-respuesta con objetos del cotidiano no religioso, como sombrilla, cuenco de plástico y muñeca, que tuvieron como finalidad despertar, en sus memorias, respuestas ancestrales, ellos fueron lo 
que Sánchez (2010) Ilama “creadores-ejecutantes", es decir, sus prácticas danzantes tuvieron sentidos, pues sus memorias fueron accionadas. Esos procesos artísticos y pedagógicos desarrollados por mí en el bloco afro Bankoma, fortalecieron "otras instancias de comportamientos humanos" (MUNANGA, 1999), arraigadas en el pasado ancestral, que presento en las figuras 2 y 3 .

Figura 2 - La bailarina Aline Santos, que tiene como inspiración la orixá Yansã, divinidad ancestral africana. En su composición coreográfica, en nivel medio del espacio, enfatiza también el verbo "sujetar" con una cuchara de madera en la sede del bloco afro Bankoma

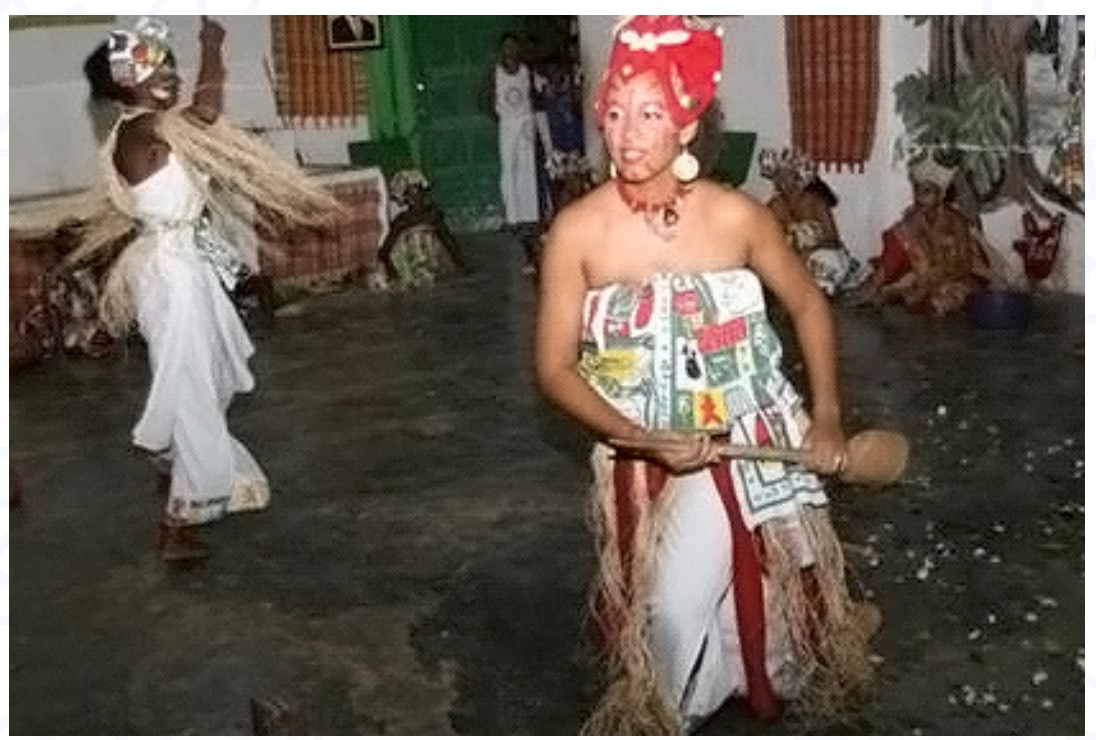

Foto: Nadir Nóbrega Oliveira(2008)

Figura 3 - Alumnas de la oficina de Técnica de Danza de Matriz Africana, durante la performance, con los trajes del bloco afro Bankoma. Géssica Catarina, Daniela y Liane demuestran el nivel medio del espacio, y movimientos de los brazos que apuntan hacia el suelo

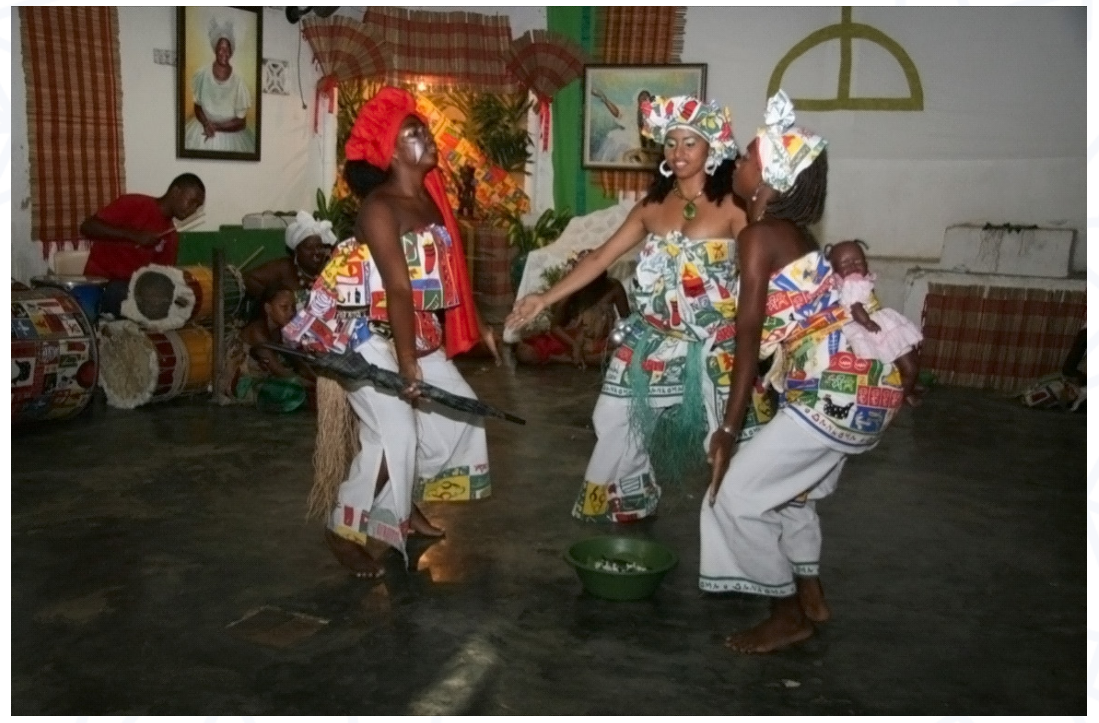

Foto: Nadir Nóbrega Oliveira (2008) 


\section{Nadir Nóbrega Oliveira}

Una de mis exalumnas, Géssica Catarina, ejemplifica ese cuerpo, ilustrando la memoria épica y su historia, expresándose poéticamente:

Mi objeto es una sombrilla que pasa a ser un bastón, porque ese bastón es de Exu y mis movimientos están relacionados con él. La sombrilla al comienzo del espectáculo va abierta hasta mi compañera de danza que la busca como si fuera un esclavo llevando a la ama. (Géssica Catarina, 2008)

En el libro A dança de Yemanjá Ogunté sob a perspectiva estética do corpo (La danza de Yemanjá Ogunté bajo la perspectiva estética del cuerpo), de la bailarina, profesora e investigadora en danza, Suzana Martins (2008), encontré estudios acerca de determinados componentes estéticos de las danzas de matrices negro-africanas, que se titulan "pilares fundamentales y estructurales", y que son visibles, tanto en coreografías de esos blocos afro como en las danzas sagradas del candomblé. Esos pilares, juntos, funcionan como "muelle propulsor de la estética negra" (MARTINS, 2008, p. 117); a saber: polirritmia o múltiplos metros, policentrismo y holismo. Martins describe la polirritmia, de acuerdo con los estudios de Asante (1985), y dice que la performance del cuerpo "usa diferentes ritmos para diferentes movimientos evolucionando de manera integral" (MARTINS, 2008, p. 118).

La autora resalta, aún, que partes del cuerpo "cabeza y manos pueden ejecutar movimientos vibratorios y, a la vez, circulares, mientras la pelvis se contrae doblando el ritmo y los pies marcan el metro del tiempo" (Ibid., p. 118). El segundo pilar, el policentrismo, también estudiado por Asante (1985), es contextualizado y definido por Martins "como moción, expandiendo tiempo y el espacio" (2008, p. 119). Ese pilar se puede observar fácilmente en los cuerpos, ejecutando la samba ljexá y la samba reggae, que se desplazan en el espacio, de manera expandida, estimulados por los toques de las percusiones. También comenta Martins que la filosofía holística fundamenta el tercer pilar, que tiene "como una de las características la conexión entre las partes del cuerpo que se mueven interactuando entre sí" (Ibid., p. 120).

En una de las secuencias de movimientos en desplazamiento en esos blocos afro, los brazos semiflexionados se elevan de manera alternada mientras se flexiona una pierna y se elevada en oposición al brazo, con el tronco 
inclinado hacia delante y girando la cabeza hacia uno y otro lado. Esas acciones son coordinaciones motrices transmitidas oralmente $y$, aparentemente, de fácil ejecución, sin embargo, como un "ser de dentro" de esos blocos afro, veo que dichas coordinaciones exigen determinadas habilidades corporales, puesto que la polirritmia, el policentrismo y el sentido holístico son componentes ejecutados de manera sutil y, naturalmente, integrados a los movimientos de los cuerpos negros.

São cuerpos negros que bailan, diariamente, transitan por las laderas, por los callejones, por las comunidades y terreiros, por los grupos de samba y también por las escuelas públicas y privadas, de la enseñanza primaria y secundaria. Así:

Las condiciones soteropolitanas de existencia singular del cuerpo bahiano se asemejan a las realidades climáticas y a la ambientación urbana, su geografía y su geopolítica, sin dejar de relacionar aun aspectos psicológicos y místicos. Todo el contexto de entorno de gestación de esta sociedad, en el grupo social y en el imaginario colectivizado de las prácticas sociales, debe ser considerado en la afirmación de estos cuerpos fáciles, ligeros, con mucho swing, no como causa, pero como un conjunto de engranajes importantes en el análisis del comportamiento encantado de este fenómeno corporal. (BARBOSA, 2006, p. 21 apud SERRANO, 2010, p. 138)

Las referencias culturales de sus cotidianos, las fiestas, el carnaval, las religiones están entrelazados en sus cuerpos, creando, así, una cultura urbana y popular en esta ciudad, a la que llaman "tierra de la felicidad", donde "todo el mundo es de Oxum." Esas danzas forman parte de las tradiciones étnico-culturales brasileñas y pueden presentarse en los cobertizos de los blocos afro, en las plazas, en los escenarios convencionales, en los terreiros o en los desfiles de carnaval, proporcionando al juerguista y al espectador la comprensión de hechos del mundo que van más allá del entretenimiento. Son narrativas históricas de un país africano imaginario o de algún lugar de la diáspora africana.

En los blocos afro, las danzas, en general, se presentan en los escenarios y en las plazas, cuya compañía de artistas, en general, se encuentra descalza, pero, durante el carnaval o en otros eventos de calle, bailarines y bailarinas llevan alpargatas de cuero sintético, zapatillas cómodas y zapatillas 


\section{Nadir Nóbrega Oliveira}

deportivas. Las danzas presentadas por esos blocos afro forman parte de lo que se conviene como danza afrobrasileña o danza afrobahiana, que presenta elementos técnicos/estéticos y corporales propios, que resalto a continuación:

- Pies planos en contacto directo con el suelo, rodillas y piernas semiflexionados, en posición paralela;

- Pies doblados y deslizando en el espacio, con dedos en media punta;

- Brazos semiflexionados, balanceándolos hacia delante y hacia atrás, y elevándolos de manera alternada;

- Movimientos ejecutados, generalmente, obedeciendo a los ritmos percusivos establecidos por los blocos: samba ljexá, Aguéré de Òxòssi, samba reggae, entre otros;

- Columna vertebral en los planos vertical y sagital (con flexión y extensión hacia delante y hacia los costados), puede ser lo que Martins (2008) Ilama getdown, visible en las danzas de matrices afrobrasileñas;

- Movimientos de bamboleo con cuadriles relajados y reaccionando a los sonidos percutidos en contratiempo con los golpes de los pies en el suelo;

- Movimientos asimétricos y circulares con paradas (pausas, expandiendo el tiempo y el espacio, contrastando con el ritmo o pulso de la música);

- Cadera en movimientos de retroversión, que en el sentido común se conocen como "cadera desencajada".

Es interesante notar que en la discusión acerca de la estética negra, esos blocos afro, desde sus fundaciones, presentan la música entrelazada a un conjunto de acciones que también forman parte de las danzas; en el modo de peinarse y arreglarse el pelo; en la creación de los vestuarios y accesorios, materializando la ancestralidad de las etnias afrobrasileñas, pues, tal como en África, la danza y la música son el alma de esos blocos afrocarnavalescos. En ese universo multicultural, esos blocos afro se presentan de manera inter y transdisciplinaria, son multidimensionales y generan impactos en muchas áreas del conocimiento humano.

Por tanto, creo que los fundamentos estéticos de la danza y de la música de esos blocos, en que el cuerpo expresa deseos, devaneos y utopías históricas, se distinguen de otras modalidades de danza y música, por ejemplo, 
la danza y la música contemporáneas. En la afirmativa de Pradier (1997, p. 13), el cuerpo es el "ugar de la encarnación de lo imaginario". Son cuerpos que captan, aprehenden, transforman y (re)crean una determinada estética, interconectados, sujetos de sus historias y dirigidos por el ritmo de la samba ijexá y de la samba reggae.

Durante los momentos de los desfiles de los blocos en las calles, los bailarines y bailarinas quedan imposibilitados(as) de actuar en el suelo. Pero, durante mis clases de técnica de danza de matriz africana, desarrolladas en el bloco afro Bankoma, los ejercicios técnicos corporales y musicales estimularon a los/las discentes a usar también el nivel bajo. Y, en las presentaciones finales de los talleres, todos lograron realizar "proezas" artísticas, en los diversos niveles.

\section{Conclusión}

Al intentar definir la estética negra en danza, no podemos estandarizarla según códigos preestablecidos, como se observa en la danza moderna o en el ballet clásico, por ejemplo. En ese sentido, el contexto sociocultural y también religioso, teniendo en vista que los blocos afro de Bahía, en su mayoría, están conectados al candomblé, presentan una gama de significados de movimientos que no se encuadra en ninguna categoría contemporánea de danza. Al contrario, la estética negra en danza evoluciona de acuerdo con sus propios principios técnicos/creativos, que tienen otra finalidad, aportan sus experiencias culturales cotidianas y su manera particular de bailar, ya sea en el colectivo, ya sea de forma individual. Los "pilares fundamentales y estructurales" - polirritmia o múltiples metros, policentrismo y holismo- señalados por Martins, son realmente visibles y funcionan como "muelle propulsor de la estética negra" (MARTINS, 2008), pero sin estandarizarla en códigos de movimiento.

En fin, las danzas de los blocos afro llê Aiyê, Olodum, Malê Debalê y Bankoma presentan elementos técnicos/creativos/estéticos, que están entrelazados a otros elementos multiculturales. Esas coreografías tienen importancia fundamental para incluirse en la historia de la danza mundial, justamente por la espectacularidad de las matrices afrobrasileñas que las componen, en el escenario carnavalesco de la ciudad de Salvador. 


\section{Referencias bibliográficas}

ALMEIDA JR., A. F. A contracultura e a política que o llê Aiyê inaugura: relações de poder na contemporaneidade. 2010. 178 f. Tese (Doutorado em Cultura e Sociedade) - Faculdade de Comunicação, Universidade Federal da Bahia, Salvador, 2010.

ANDRADE, M. de. Danças dramáticas do Brasil. Belo Horizonte: Itatiaia, 1982.

ASANTE, K. W. Commonalities in african dance: an aesthetic foundation. In: ASANTE, M. K.; ASANTE, K. W. African culture: the rhythms of unity. New Haven: Greenwood, 1985.

BRASIL. Lei $n^{\circ}$ 11.645, de 10 de março de 2008. Altera a Lei oㅜ 9.394, de 20 de dezembro de 1996, modificada pela Lei no 10.639, de 9 de janeiro de 2003, que estabelece as diretrizes e bases da educação nacional, para incluir no currículo oficial da rede de ensino a obrigatoriedade da temática "História e Cultura Afro-Brasileira e Indígena". Diário Oficial da União. Poder Legislativo. Brasília, DF, 11 mar. 2008. Seção 1, p. 1. Disponível em: <https://goo.gl/mmjVqR>. Acesso em: 17 jul. 2016.

BIÃO, A. Etnocenologia, uma introdução. In: GREINER, C.; BIÃO, A. (org.). Etnocenologia: textos selecionados. São Paulo: Annablume, 1999. p. 15-22.

$\mathrm{BIÃO}$, A. et al. (org.). Temas em contemporaneidade, imaginário e teatralidade. São Paulo: Annablume, 2001.

CUNHA JR., H. A História Africana e os elementos básicos para seu ensino. In: LIMA,

I. C.; ROMÃO, J. (org.). Negros e currículo. Florianópolis: Atilènde, 2001. (Série Pensamento Negro em Educação, Vol. 2).

JEUDY, H.-P. O corpo como objeto de arte. São Paulo: Estação Liberdade, 2002. LABAN, R. Domínio do movimento. São Paulo: Summus, 1978.

LUZ, N. C. P. Bahia a Roma negra: estratégias comunitárias e educação pluricultural. In: CONGRESSO BRASILEIRO DE CIÊNCIAS DA COMUNICAÇÃO INTERCOM, 25., 2002, Salvador. Anais... Salvador: Sociedade Brasileira de Estudos Interdisciplinares da Comunicação, set. 2002. p. 1-18.

MACEDO, M. J. Abdias do Nascimento: a trajetória de um negro revoltado (1913-1968). 2006. 285 f. Dissertação (Mestrado em Sociologia) - Faculdade de Filosofia Letras e Ciências Humanas, Universidade de São Paulo, São Paulo, 2006. MARTINS, S. A dança de Yemanjá Ogunté sob a perspectiva estética do corpo. Salvador: EGBA, 2008.

MELO, G. Divina, tu és, Mercedes Baptista! Salgueiro, Rio de Janeiro, 18 ago. 2014. Disponível em: <http://bit.ly/2vCSRtG>. Acesso em: 27 jun. 2015.

MUNANGA, K. Rediscutindo a mestiçagem no Brasil: Identidade nacional versus identidade negra. Petrópolis: Vozes, 1999. (Coleção Identidade Brasileira).

OLIVEIRA, N. N. Dança afro-sincretismo de movimentos. Salvador: Ufba, 1991. 
Agô Alafiju, Odara! A presença de Clyde Wesley Morgan na Escola de Dança da UFBA, de 1971 a 1978. 2006. 317 f. Dissertação (Mestrado em Artes Cênicas) - Programa de Pós-Graduação em Artes Cênicas, Universidade Federal da Bahia, Salvador, 2006.

Sou negona, sim senhora! Um olhar nas práticas espetaculares dos blocos afro llê Aiyê, Olodum, Malê Debalê e Bankoma no carnaval soteropolitano. 2013. 254 f. Tese (Doutorado em Artes Cênicas) - Programa de Pós-Graduação em Artes Cênicas, Universidade Federal da Bahia, Salvador, 2013.

PEREIRA, R. A formação do balé brasileiro: nacionalismo e estilização. Rio de Janeiro: FGV, 2003.

PRADIER, J.-M. Etnocenologia: a carne do espírito. Tradução Armindo Bião. Revista Repertório: Teatro e Dança, Salvador, n. 1, p. 9-21, 1997.

SÁNCHEZ, L. M. M. A dramaturgia da memória no teatro-dança. São Paulo: Perspectiva, 2010.

SERRANO, L. S. Corpografias: uma leitura corporal dos intérpretes-criadores do grupo Dimenti. 2010. 215 f. Tese (Doutorado em Artes Cênicas) - Programa de Pós-Graduação em Artes Cênicas, Universidade Federal da Bahia, Salvador, 2010. SILVA JR., P. M. Mercedes Baptista: a criação da identidade negra na dança. Brasília, DF: Fundação Cultural Palmares, 2007.

Recibido el 26/06/2017

Aprobado el 26/06/2017

Publicado el 05/09/2017 